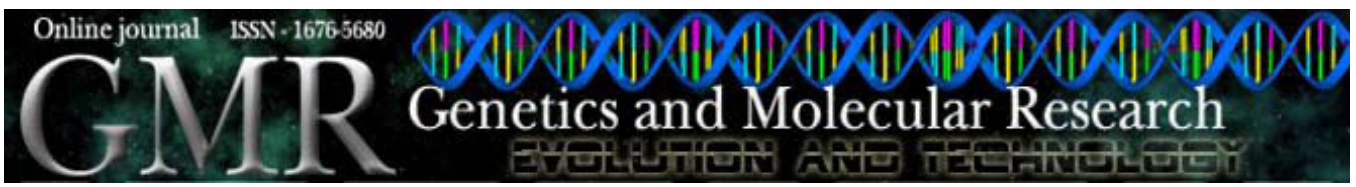

Short Communication

\title{
Polyandry in the red-headed river turtle Podocnemis erythrocephala (Testudines, Podocnemididae) in the Brazilian Amazon
}

\author{
C. Fantin ${ }^{1,2}$, I.P. Farias ${ }^{1}$, L.A.S. Monjeló ${ }^{1}$ and T. Hrbek ${ }^{3}$ \\ ${ }^{1}$ Departamento de Biologia, Laboratório de Evolução e Genética Animal, \\ Universidade Federal do Amazonas, Manaus, AM, Brasil \\ ${ }^{2}$ Departamento de Biologia, Universidade do Estado do Amazonas, \\ Manaus, AM, Brasil \\ ${ }^{3}$ Biology Department, University of Puerto Rico-Rio Piedras, San Juan, Puerto Rico \\ Corresponding author: C. Fantin \\ E-mail: cleitonfantin@hotmail.com
}

Genet. Mol. Res. 9 (1): 435-440 (2010)

Received November 29, 2009

Accepted January 4, 2010

Published March 16, 2010

\begin{abstract}
The genus Podocnemis comprises six living species, including $P$. erythrocephala (irapuca - red-headed river turtle). Data are available concerning the reproductive biology of the species of the genus Podocnemis, but little is known about their reproductive strategies. Considering the total lack of such data for P. erythrocephala, and with the goal of contributing information on their mode of reproduction, we examined the relationships among individuals of nests of this turtle, using microsatellite markers. Using four microsatellite loci, we analyzed the progeny in six nests from two localities in the Brazilian Amazon (Santa Isabel do rio Negro and Parintins). All juveniles from each nest were analyzed. The genotypes of each juvenile from each nest were identified, and because a sample of female DNA was not available, the maternal genotype was inferred from homozygous individuals in each nest. We found that this species is promiscuous; there was multiple paternity in five of the six nests analyzed. In addition to being important for the understanding of evolutionary and genetic processes, this type of information will be useful for chelonian management projects. Our data suggest one possible
\end{abstract}


difference between reproductive patterns of the different populations. This multi-paternal condition may be a natural reproductive strategy for the preservation of the genetic diversity of this species.

Key words: Chelonian; Podocnemis erythrocephala; Irapuca; Microsatellite; Paternity; Mating system

\section{INTRODUCTION}

Podocnemis erythrocephala is easily distinguished from its congeners by its small size, less than $32 \mathrm{~cm}$. Generally, the females are larger than the males and measure around 27 $\mathrm{cm}$. Color ranges from dark brown to black, and the carapace is expanded in the rear portion; it has a pair of barbels under its chin, and a bright red stripe that extends from the part behind its head to the tympanum (Pritchard and Trebbau, 1984). Various authors, including Wermuth and Mertens (1961), state that $P$. erythrocephala occupies a large area in the north of South America. However, Mittermeier and Wilson (1974) report that the samples with reliable information on origin were all collected in the Negro River system. The species is almost completely confined to black water rivers, and the majority of the known specimens are from the Negro River. In this river system, the species displays preference for small black water lakes and their feeder water courses, and is rarely found in the main river channel.

The floodplain soil is generally utilized by $P$. erythrocephala for nesting (Pritchard and Trebbau, 1984). This species lays its eggs between the end of August to the beginning of November on the Negro River beaches, with the peak apparently occurring between September and October. The number of eggs varies from 5 to 14, and egg-laying generally occurs at night in sandy areas called "campinas". Although this species is no longer economically important, it is extensively hunted along the Negro River for its meat and eggs.

Reproductive biology studies, including the types of paternity, are not only important in analyzing evolutionary and genetic factors, but also provide information that is helpful in the management projects for chelonians (Andrade, 2004). Thus, considering the total lack of data on the type of paternity in P. erythrocephala, and with the aim of contributing to our knowledge of the pattern of its mode of reproduction, this study was carried out to determine the kinship among the individuals in each P. erythrocephala nest by means of microsatellite molecular markers.

\section{MATERIAL AND METHODS}

We used six nests of P. erythrocephala from two localities in the Brazilian Amazon for the study of paternity. Of these nests, four were collected in Santa Isabel do rio Negro (nests 1, 2, 3, and 4), and two in Parintins, central Amazon River (nests 5 and 6). After hatching, $50-\mu \mathrm{L}$ blood samples were drawn, and the animals were returned to the environment where they were collected. The number of juvenile turtles sampled represented the total number of offspring born in each nest $(\mathrm{N} 1=7, \mathrm{~N} 2=6, \mathrm{~N} 3=5, \mathrm{~N} 4=8, \mathrm{~N} 5=6, \mathrm{~N} 6=5)$. Blood samples of 37 juveniles were collected by femoral vein puncture using a 1-mL syringe and subsequently stored in Eppendorf tubes with $500 \mu \mathrm{L}$ absolute ethanol.

Total genomic DNA was extracted using GFX DNA extraction kit (GE-Healthcare). Genomic DNA of each individual was amplified by polymerase chain reaction (PCR) using the technique of Schuelke (2000). Of the four microsatellite primers used in PCR, two were devel- 
oped by Fantin et al. (2007) (Puni_1D9 and Puni_1E1), and two by Valenzuela (2000) (PE344 and PE519). The PCR products were diluted in a proportion of 1:100, and the size marker ROX pUC-19, modified from Dewoody et al. (2004), was added to determine sizes of observed alleles. Genotyping of the amplified DNA was determined in an ABI 3130xl automatic sequencer, and the alleles observed in each individual were analyzed using the GeneMapper v.4.0 program.

The method used to test for multiple paternity was the simple counting of alleles (Myers and Zamudio, 2004), which consists in the counting of alleles represented within each nest. Another method used to establish multiple paternity was the inference of parental genotypes. The maternal alleles were identified by the presence of homozygous juveniles for each locus within a nest. When one parental allele could be inferred, one could then infer multiple paternity for a nest when a locus examination indicated the presence of four alleles in the nest. In addition, if two different kinds of homozygotes could be detected, the presence of three alleles in situ indicated multiple paternity. The coefficient of relationship $(r)$ between pairs of individuals was obtained using the KINSHIP 1.3 program (Godnight and Queller, 1999). It is assumed that for values of $r$ around 0.12 , individuals are considered to be cousins, while 0.25 indicates half-sibs and 0.50 or greater, full-sibs (Blouin, 2003). From these values of relatedness, resulting in a symmetric matrix, a graph was constructed to better visualize the degree of kinship between individuals from the same nest.

The probability of paternity exclusion $(Q)$ was determined using the method described by Weir (1996). Based on the allelic frequencies of the 4 microsatellite loci, the probability of genetic identity (I) was calculated locus by locus and combined according to Paetkau et al. (1995).

\section{RESULTS}

Of the six P. erythrocephala nests analyzed, only one did not show paternity (nest 6). Our analyses, by means of allele counting and inference of the maternal genotypes, showed evidence of a minimum of two males contributing to the nests where multiple paternity exists. The frequency of the number of alleles per locus is presented in Table 1, where we can see that the minimum number of alleles/locus observed was one (nest 6) and the maximum six (nest 4). In nest 4, the analysis of locus PE519 by the simple method of counting alleles without inference of maternal alleles showed that the presence of these six alleles is already indicative of the contribution of more than one male in the offspring. Analysis of locus Puni_1E1 in nest 3 via the simple counting method also provided evidence of the contribution of extra males to the young of this nest via the inference of five alleles. For the four microsatellite loci utilized, the probability of two unrelated individuals having the same genotype (probability of identity) was $1.59 \times 10^{-4}$. The probability of $Q$ with a single locus varied from $33.91 \%$ (Puni_1D9) to $60.99 \%$ (PE519), and when all the loci were combined, it was $95.07 \%$, showing a reasonable power of detection of multiple paternity in this species.

Table 1. Number of alleles shared between parents (inferred from the presence of homozygous juveniles)/
number of alleles found for each locus in the nests of Podocnemis erythrocephala.
\begin{tabular}{llllllll}
\hline Locus & $\mathrm{N} 1$ & $\mathrm{~N} 2$ & $\mathrm{~N} 3$ & $\mathrm{~N} 4$ & $\mathrm{~N} 5$ & $\mathrm{~N} 6$ \\
\hline Puni_1D9 & $2 / 2$ & $\mathbf{2 / 3}$ & $1 / 3$ & $1 / 3$ & $1 / 2$ & $1 / 2$ \\
Puni_1E1 & $\mathbf{2 / 4}$ & $\mathbf{2 / 3}$ & $\mathbf{1 / 5}$ & $0 / 4$ & $1 / 3$ & $0 / 1$ \\
PE344 & $0 / 3$ & $0 / 4$ & $0 / 3$ & $\mathbf{1 / 4}$ & $0 / 3$ & $2 / 2$ \\
PE519 & $1 / 4$ & $\mathbf{2} / \mathbf{4}$ & $1 / 2$ & $\mathbf{1 / 6}$ & $\mathbf{1 / 4}$ & $0 / 3$ \\
\hline
\end{tabular}

Results in bold indicate the presence of multiple paternity. 
When analyzed by the KINSHIP program, almost all the P. erythrocephala nests show similar distributions of relationship patterns (Figure 1). The majority of the nests (except nest 6) had $r$ values below 0.5 , indicating the presence of other categories of relationships in addition to full-sib among the young, providing evidence of the existence of the contribution of more than one male to the pool of offspring.
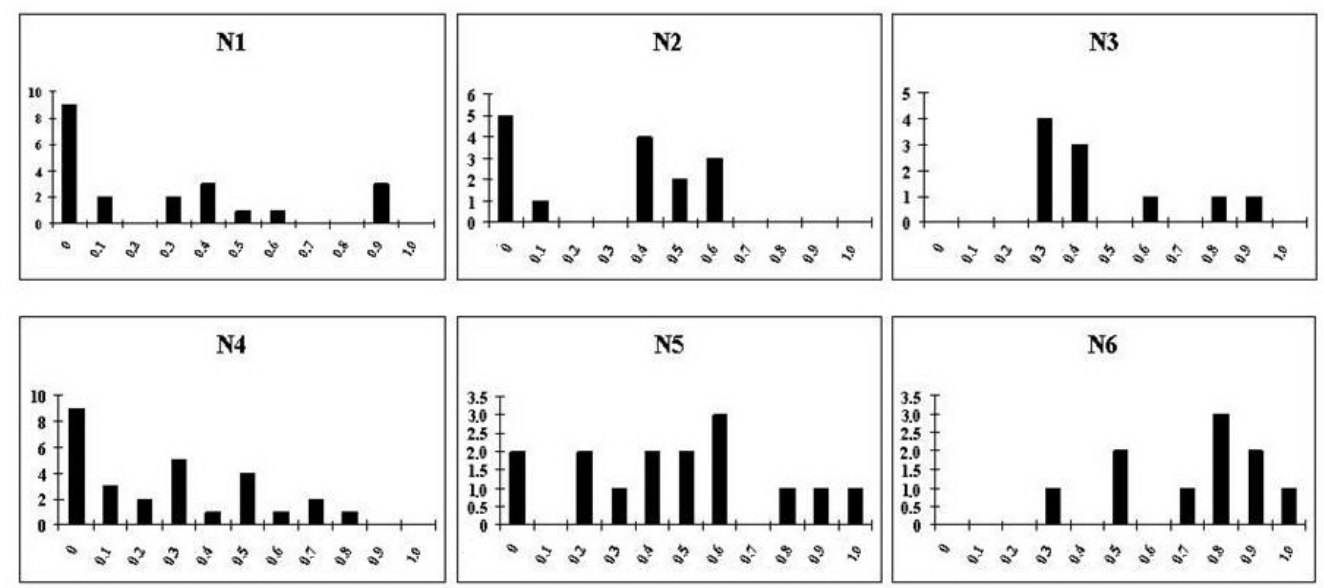

Figure 1. Graphs of kinship among offspring of Podocnemis erythrocephala, for each nest analyzed, where x-axis indicates the coefficient of relationship and y-axis the frequency. It is assumed that for values of $r$ (coefficient of relationship) around 0.12 , individuals are considered to be cousins, while 0.25 indicates half-sibs and 0.50 or greater, full-sibs.

\section{DISCUSSION}

Among the existing studies of paternity in the genus Podocnemis, we can cite Valenzuela (2000) and Pearse et al. (2006) for P. expansa and Fantin et al. (2008) for P. unifilis. Valenzuela (2000) and Pearse et al. (2006), utilizing microsatellite markers, reported the existence of multiple paternity in $P$. expansa nests. Pearse et al. (2006) found multiple paternity in only $10.3 \%$ of the nests analyzed, contrasting with the $100 \%$ reported by Valenzuela (2000). Fantin et al. (2008) used eight microsatellite loci in 66 offspring of six nests of $P$. unifilis, on a central Amazon River beach in Amazonas, Brazil, and found that P. unifilis females exhibited a promiscuous mating system (polyandry) with all nests being fathered by at least two males.

Little is known about the mating system of P. erythrocephala. Ferrara (2007) studied the reproductive behavior of $P$. erythrocephala in captivity, by means of observations of the courting and copulation behavior, sexual selection according to size of carapace and head, cephalic coloration, and the influence of water temperature on courtship behavior. According to Ferrara (personal communication), behavioral and observational data demonstrated that the females frequently copulate with different males, though the possible occurrence of multiple paternity has never been investigated before.

As every progeny inherits one maternal and one paternal allele, each member of the nest must consequently inherit one of the two maternal alleles and one of the paternal alleles; the 
number of paternal alleles present in the nest will depend on the number of fathers contributing to the young of the next. The parental alleles of the P. erythrocephala nests were identified by the presence of homozygotes for each locus in hatchlings within a nest (Table 1). After the inference of the parental alleles, it was possible to identify multiple paternity in nests $1,2,3,4$, and 5 . If we had only utilized the method of simple counting of alleles, without inference of the parental genotype, we could only have identified multiple paternity in nests 3 and 4 . However, even after we identified the alleles of the parental genotypes, nest 6 continued to show single paternity.

The existence of multiple paternity in the P. erythrocephala nests is also demonstrated in the results of the graphs generated from the coefficient of relationship values among the hatchlings (Figure 1). When we analyzed the relationship categories, we found that all nests showed $r$ values of less than 0.5 , with the exception of nest 6 , which showed much higher values of $r$. Given that one calculates coefficient of relationship values as the fraction of alleles that are shared among the descendants, it is assumed that for $r$ values less than 0.50 , the degree of kinship among individuals of the same nest is more distant than for a full-sib relationship, supporting the hypothesis of the contribution of extra fathers to the offspring.

In the $P$. erythrocephala nests indicating multiple paternity, a minimum of two male contributors to the groups of offspring can be inferred. We must remember that the method of counting alleles provides us with only an estimate of the minimum number of males that contribute genetically to the progeny. The method makes no distinction for multiple fathers that have alleles in common, and thus, we may exclude a male's contribution to the clutch of offspring, due to the sharing of alleles among males. However, the use of sufficient numbers of highly polymorphic loci would allow all of the uncertainties to be resolved.

This study provides evidence of the existence of multiple paternity in P. erythrocephala. However, our data suggest a possible difference between the reproductive patterns of different populations. It would be interesting, in future studies, to compare nests from different localities so as to verify whether there is a difference in the reproductive pattern among populations of this species, thereby enabling the development of management programs that are suitable for different localities. These studies provide essential information for estimating the relative contribution of pairs involved in matings, considering it as a natural reproductive strategy for conservation of this species' genetic diversity.

\section{ACKNOWLEDGMENTS}

The authors thank the "Pé-de-Pincha" turtle project for helping in the collection of samples. Research supported by grants to I.P. Farias from PPG7/CNPq (\#557090/2005-9) and to T. Hrbek from the Sequencing and Genotyping Facility of the University of Puerto Rico-Rio Piedras. Permission to collect tissue samples was granted by RAN/IBAMA, \#113/2006. This study is part of a Ph.D. thesis presented by C. Fantin in the Biotechnology Program of Universidade Federal do Amazonas; C. Fantin was supported by a Ph.D. fellowship from SUFRAMA.

\section{REFERENCES}

Andrade PCM (2004). Criação e Manejo de Quelônios no Amazonas (Projeto Diagnóstico da Criação de Animais Silvestres no Estado do Amazonas). IBAMA/UFAM/SDS, Manaus.

Blouin MS (2003). DNA-based methods for pedigree reconstruction and kinship analysis in natural populations. Trends Ecol. Evol. 18: 503-511. 
Dewoody JA, Schupp J, Kenefic L, Busch J, et al. (2004). Universal method for producing ROX-labeled size standards suitable for automated genotyping. Biotechniques 37: 348, 350, 352.

Fantin C, Carvalho CF, Hrbek T, Sites JW Jr, et al. (2007). Microsatellite DNA markers for Podocnemis unifilis, the endangered yellow-spotted Amazon River turtle. Mol. Ecol. Notes 7: 1235-1238.

Fantin C, Viana LS, Monjeló LAS and Farias IP (2008). Polyandy in Podocnemis unifilis (Pleurodira; Podocnemididae), the vulnerable yellow-spotted Amazon River turtle. Amphibia-Reptilia 29: 479-486.

Ferrara CR (2007). Comportamento Reprodutivo de Podocnemis erythrocephala (Spix 1824)(Testudines, Podocnemididae) em Cativeiro. Master's thesis, Instituto Nacional de Pesquisa da Amazônia - INPA/UFAM, Manaus.

Godnight KF and Queller DC (1999). Computer software for performing likelihood tests of pedigree relationship using genetic markers. Mol. Ecol. 8: 1231-1234.

Mittermeier RA and Wilson RA (1974). Redescription of Podocnemis erythrocephala (Spix, 1824), an Amazonian pelomedusid turtle. Pap. Avul. Zool. 28: 147-162.

Myers EM and Zamudio KR (2004). Multiple paternity in an aggregate breeding amphibian: the effect of reproductive skew on estimates of male reproductive success. Mol. Ecol. 13: 1951-1963.

Paetkau D, Calvert W, Stirling I and Strobeck C (1995). Microsatellite analysis of population structure in Canadian polar bears. Mol. Ecol. 4: 347-354.

Pearse DE, Dastrup RB, Hernandez O and Sites JW Jr (2006). Paternity in an Orinoco population of endangered arrau River Turtles, Podocnemis expansa (Pleurodira; Podocnemididae), from Venezuela. Chelonian Conserv. Biol. 5: 232-238.

Pritchard PCH and Trebbau P (1984). The Turtles of Venezuela. Society for the Study of Amphibians and Reptiles, Ann Arbor.

Schuelke M (2000). An economic method for the fluorescent labeling of PCR fragments. Nat. Biotechnol. 18: 233-234.

Valenzuela N (2000). Multiple paternity in side-neck turtles Podocnemis expansa: evidence from microsatellite DNA data. Mol. Ecol. 9: 99-105.

Weir BS (1996). Genetic Data Analysis II: Methods for Discrete Population Genetic Data. Sinauer Associates, Sunderland. Wermuth H and Mertens R (1961). Schildkröten, Krokodile, Brückenechsen. Gustav Fischer Verla, Jena. 